ORIGINAL ARTICLE

\title{
Functional preparedness of women of the first period of mature age of different somatotypes
}

\author{
Viacheslav M. Miroshnichenko ${ }^{1 \mathrm{ABCDE}}$, Yuriy M. Furman ${ }^{1 \mathrm{ABDE}}$, Viktoriia Yu. Bohuslavska ${ }^{1 \mathrm{ABDE}}$, Oleksandra Yu. \\ Brezdeniuk $^{1 \mathrm{ABDE}}$, Svitlana V. Salnykova ${ }^{2 \mathrm{ABDE}}$, Oksana P. Shvets ${ }^{1 \mathrm{ABDE}}$, Maryna O. Boiko ${ }^{1 \mathrm{ABDE}}$ \\ ${ }^{1}$ Vinnytsia Mykhailo Kotsiubynskyi State Pedagogical University, Ukraine \\ ${ }^{2}$ Vinnytsia Institute of Trade and Economics of Kyiv National University of Trade and Economics, Ukraine
}

Authors' Contribution: A - Study design; B - Data collection; C - Statistical analysis; D - Manuscript Preparation; E - Funds Collection

\begin{abstract}
Background It is believed that the somatotype is a predictor of indicators of functional readiness. There are significant and Study Aim differences in the aerobic performance of the body for people of different somatotypes among students girls and men. Features of manifestation of anaerobic possibilities of an organism at persons of various somatotypes from 7 to 30 years old are described. We can assume that women of the first adulthood period of different somatotypes, indicators of functional readiness are manifested in different ways. The aim of the study was to identify the features of aerobic, anaerobic lactate and anaerobic alactate productivity of women of the first period of mature age of different somatotypes.
\end{abstract}

Material and The study involved 210 females 25-35 years old. Somatotype was determined in all subjects. Functional Methods readiness was determined by indicators of anaerobic lactatic productivity, anaerobic alactatic productivity and aerobic productivity of the organism. The power of aerobic energy supply processes was investigated by $\mathrm{VO}_{2 \max }$. To determine the $\mathrm{VO}_{2 \max }$ used cycling ergometric version of the PWC 170 test. The subjects was performed a stepwise increasing load on the ergometer to determine the TAM. At the end of each stage, heart rate was recorded. The TAM level corresponded to the inflection point on the heart rate growth chart. The capacity of anaerobic lactate processes of energy supply was investigated by indicator of the maximum quantity of mechanical work for 1 minute (MQMK). The subjects performed a bicycle ergometric load duration $1 \mathrm{~min}$ with a power of $225 \mathrm{~W}$ with a maximum pedaling frequency. The power of anaerobic lactate processes of energy supply was determined by the Wingate anaerobic test WAnT 30. The power of anaerobic alactate processes of energy supply was determined by the test WAnT 10. Statistical processing was performed using the program STATISTICA 13.

Results According to absolute indicators (WAnT10. WAnT30. MQMK, TAM, $\mathrm{VO}_{2 \max }$ ) the advantage of representatives of endomorphic-mesomorphic somatotype was established. According to relative indicators of aerobic productivity $\left(\mathrm{TAM}, \mathrm{VO}_{2 \max }\right.$ ) representatives of the ectomorphic and balanced somatotype predominate.

Conclusions: High values of absolute indicators of functional readiness are associated with high values of body mass in combination with a high percentage of muscle for women of different somatotypes. Accordingly, for representatives of somatotypes with lower body mass are characterized by lower absolute values of all indicators of functional fitness. The relative indicators of aerobic productivity are dominated by representatives of somatotypes, which are characterized by lower body mass.

Keywords: aerobic, anaerobic productivity, somatotype, females.

\section{Introduction}

In the field of sp orts, the possibilities of using the somatotype have been thoroughly studied. Somatotype is taken into account in sports selection, sports orientation and training. Based on the somatotype, morpho-functional models are developed as a reference point for achieving a certain level of preparedness. Over the past few years, significant progress has been made in the development of technologies for diagnosing functional readiness. Thus, modern cycling computers and running heart rate monitors allow you to determine the threshold of anaerobic metabolism and maximum oxygen consumption without special laboratory testing. To determine the anaerobic component of functional fitness, tests have

\footnotetext{
(c) Viacheslav M. Miroshnichenko, Yuriy M. Furman,

Viktoriia Yu. Bohuslavska, Oleksandra Yu. Brezdeniuk,

Svitlana V. Salnykova, Oksana P. Shvets, Maryna O. Boiko, 2021

doi:10.15561/26649837.2021.0504
}

been developed that can be performed in a regular fitness center. The availability of diagnostics has caused the need for physically active people to monitor their own level of functional fitness. This created a request to study the features of functional fitness of people of different somatotypes not related to sports.

Goran Spori et al. [1] found statistically significant difference in the values of maximum oxygen consumption $\left(\mathrm{VO}_{2 \max }\right)$ in military sailors of different somatotypes. Sukanta Saha [2] found that somatotype components (endomorphy, ectomorphy, mesomorphy) are well correlated with $\mathrm{VO}_{2 \max }$. Dulo et al. [3] found significantly higher absolute indicators of physical performance (PWC 170) and $\mathrm{VO}_{2 \text { max }}$ women of endomorphic-mesomorphic somatotype, compared with other somatotypes. Neha Parve et al. [4] proved the relationship between somatotype, height, body weight and $\mathrm{VO}_{2 \max }$. In our previous studies, we found a significant advantage of 
ectomorphic and balanced somatotype in the relative indicator of maximum oxygen consumption $\left(\mathrm{VO}_{2 \max }\right)$ in girls 17-19 years [5].

Zimnitskaya et al. [6] studied the threshold of anaerobic metabolism and the threshold of aerobic metabolism 25-35 years women of different somatotypes. The authors found higher performance of asthenics at the level of thresholds of aerobic and anaerobic metabolism in relative terms and higher performance of normosthenics in absolute terms.

In the modern scientific literature, less attention has been paid to the study of anaerobic productivity in nonathletes. Investigating the anaerobic lactate productivity of girls 17-19 years old in absolute terms of the maximum quantity of mechanical work for 1 minute (MQMK), we found a predominance of endomorphic and endomorphicmesomorphic somatotype. According to the relative indicator of the maximum quantity of mechanical work for 1 minute, no statistically significant differences were found in the representatives of different somatotypes [5]. The determining role of somatotype in relation to the level of anaerobic lactatic productivity in men $26 \pm 8.9$ years old is indicated by Ryan-Stewart et al. [7]. In addition, the authors note that a third of strength indicators are predicted by somatotype. But such conclusions were made by the authors on the basis of the analysis of strength exercises, instead of functional tests. Furman et al. [8] established the standards of functional fitness of girls 17-19 years for the whole spectrum of energy supply of muscular activity, but this work does not take into account the somatotype of the subjects. Dulo [9] studied anaerobic alactic and anaerobic lactatic productivity in girls from 16 to 20 years old. The author found significantly higher values of the absolute indicators of the Wingate anaerobic test WAnT10 and WAnT30 in the endomorphic-mesomorphic somatotype. According to the relative indicators of WAnT10 and WAnT30 found significantly lower values in ectomorphic and endomorphic somatotype. Çinarli et al. [10] studied the anaerobic capacity of men of different somatotypes $22.1 \pm 2.46$ years old according to the WAnT test 30 . The authors found that the relative values of peak power and average anaerobic power in different somatotypes do not have statistically significant differences $(p>0.05)$.

Studies of the features of the manifestation of indicators of functional fitness of women of the first period of adulthood of different somatotypes for the whole spectrum of energy supply of muscular activity (aerobic, anaerobic alactic and anaerobic lactatic) were not found. Similar studies were conducted by Kornienko et al. [11], but with a different age group. The authors investigated all modes of energy supply of muscular activity in boys and girls 7-17 years of age of different somatotypes. The difference in representatives of different somatotypes for indicators of power and capacity of aerobic and anaerobic productivity of organism is established. Features of these differences are strongly expressed at teenagers. The authors state that sometimes differences in the somatotype by more values than gender differences. Kaur et al. [12], Nikolic et al. [13], indicate to age-related changes in the relationship of components of the somatotype. Therefore, information about the functional preparedness of representatives of different somatotypes from one age group to another can not be correctly transmitted.

There is a need to test the hypothesis that women of the first period of adulthood of different somatotypes the indicators of functional readiness are differently manifested.

The aim of the study was to identify the features of aerobic, anaerobic lactate and anaerobic alactate productivity of women of the first period of mature age of different somatotypes.

\section{Material and Methods}

Participants. The study involved females 25-35 years old (the first period of mature age) $n=210$. All subjects in the past had no experience in sports. Each subject gave written consent to participate in the experiment.

Procedure. Initially, somatotype was determined for all subjects by the Carter et al. [14] method.

Functional readiness is determined for indicators of aerobic alactic, anaerobic lactatic and aerobic productivity. The power of aerobic energy supply processes of muscular activity was investigated by the indicator of maximum oxygen consumption $\left(\mathrm{VO}_{2 \text { max }}\right) \cdot \mathrm{VO}_{2 \max }$ was determined by the Karpman et al. [15] method. For this purpose was used a bicycle ergometric test of the PWC 170 version. The subjects performed two loads of different power. The power of the first load $\left(\mathrm{N}_{1}\right)$ was $1 \mathrm{~W}$ per $1 \mathrm{~kg}$ of body weight, the other $\left(\mathrm{N}_{2}\right)-2 \mathrm{~W}$ per $1 \mathrm{~kg}$ of body weight. Pedaling frequency - 60 revolutions per 1 minute. The duration of each load was 5 minutes with 3 minutes interval. At the end of each load, the heart rate $\left(f_{1}\right.$ and $f_{2}$ ) was determined. PWC 170 was calculated according to the algorithm [16]. To determine the values of $\mathrm{Vo}_{2 \max }$, the value of PWC 170 abs was substituted into equation 1:

$$
\mathrm{VO}_{2 \text { max abs. }}=1,7 \cdot \mathrm{PWC}_{170 \text { abs. }}+1240 \text {, }
$$

where $\mathrm{VO}_{2 \text { max abs. }}$ displayed in $\mathrm{ml} \cdot \mathrm{min}^{-1} ; \quad \mathrm{PWC}_{170 \text { abs. }}$ displayed in $\mathrm{kg} \cdot \mathrm{min}^{-1}$

The threshold of anaerobic metabolism (TAM) was determined by the test of Conconi et al. [17] in a modification of Furman [18, Art. 37-38]. The subjects performed a stepwise increasing load on the ergometer starting from a power of 60 watts, adding 10 watts at each stage. The duration of work and the frequency of pedaling at each stage are constant - the duration is $40 \mathrm{~s}$, and the frequency is $60 \mathrm{rpm}^{-1}$. At the end of each stage, heart rate was recorded. The level of TAM corresponded to the inflection point on the graph of heart rate growth. Results were presented in $\mathrm{W}$.

To determine the capacity of anaerobic lactatic energy supply processes of muscular activity was used a method developed by Shogy et al. [19]. This method involves determining the maximum quantity of mechanical work for 1 minute (MQMK). The subject performed a bicycle ergometric load with 1 min duration, power of $225 \mathrm{~W}$ and maximum pedaling frequency. Results were presented in 
$\mathrm{kg} \cdot \min ^{-1}$.

The power of anaerobic alactatic energy supply processes of muscular activity was determined using the Wingate anaerobic test WAnT10 [20]. This test consists in performing a bicycle ergometric load 10sec duration with a power of $225 \mathrm{~W}$ and maximum possible pedaling frequency. The number of full pedal revolutions was counted. By mathematical calculations, the result was expressed in $\mathrm{kg} \cdot \mathrm{min}^{-1}$.

The power of anaerobic lactatic energy supply processes of muscular activity was determined using the Wingate anaerobic test (WAnT30) [20]. The conditions of this test are similar to the WAnT10 test. The difference is duration of the load that lasted 30 seconds. Result was expressed in $\mathrm{kg} \cdot \mathrm{min}^{-1}$.

To increase the informativeness of all indicators, absolute and relative values were studied. All tests were performed on a Christopeit Sport AX-1 bicycle ergometer (Christopeit, Germany).

Statistical analysis. Independent samples were compared, where the series reflected the trait in representatives of different somatotypes. Initially, the data series were checked using STATISTICA 13 for compliance with the normal distribution law. Data that corresponded to the normal distribution law were compared according to Student's t- criterion. Determined: $\bar{X}$ - arithmetic mean, $\mathrm{S}$ - standard deviation, $\mathrm{t}$ - value of Student's t-criterion, $\mathrm{p}-$ level of significance. The difference was considered significant at a significance level of $\mathrm{p}<0.05$.

\section{Results}

The study of the power of anaerobic alactatic processes of energy supply in women of different somatotypes revealed were defined the predominance of representatives endomorphic-mesomorphic somatotype. Value of indicator WAnT $10_{\text {abs }}$ in women with the endomorphic-mesomorphic somatotype is statistically significantly greater than the value of representatives all other somatotypes $(p<0.05)$. In turn, the representatives of the endomorphic somatotype are dominated by women of ectomorphic and balanced somatotypes $(\mathrm{p}<0.05)$. Value of indicator WAnT $10_{\text {abs }}$ in representatives ectomorphic and balanced somatotypes do not have statistically significant differences ( $\mathrm{p}>0.05)$ (table 1$)$.

The calculation of the indicator WAnT $10_{\text {abs. }}$ per $\mathrm{kg}$ of body mass of the subjects slightly changes the picture. According to the indicator of WAnT $10_{\text {rel. }}$ the value of the representatives of the endomorphic-mesomorphic somatotype exceeds the value of the representatives of all other somatotypes $(p<0.05)$. Representatives of the endomorphic somatotype have an advantage only over women of the ectomorphic somatotype $(p<0.05)$. The lowest values of the indicator of WAnT $10_{\text {rel. }}$ have representatives of ectomorphic and balanced somatotypes, which do not have a statistically significant difference $(\mathrm{p}>0.05)$ (table 1).

During an investigation of the power of anaerobic lactatic processes of energy supply according to the indicator WAnT 30abs. were found an advantage of representatives of endomorphic-mesomorphic somatotype over representatives of all other somatotypes $(p<0.05)$. The value of representatives of endomorphic somatotype prevails over representatives of ectomorphic and balanced somatotypes $(p<0.05)$. The values of ectomorphic and balanced somatotypes are the lowest and do not have statistically significant differences $(\mathrm{p}>0.05)$ (table 2$)$.

Table 1. Power of anaerobic alactic processes of energy supply of women 25-35 years with different somatotypes

\begin{tabular}{|c|c|c|c|c|}
\hline \multirow[t]{2}{*}{$\begin{array}{l}\text { Somatotype } \\
\text { groups }\end{array}$} & $\begin{array}{l}\text { WAnT } 10 \\
\left(\mathrm{~kg} \cdot \mathrm{min}^{-1}\right)\end{array}$ & $\begin{array}{l}\text { The level of significance } \\
\text { of the t-criterion }\end{array}$ & $\begin{array}{l}\text { WAnT } 10 \\
\left(\mathrm{~kg} \cdot \mathrm{min}^{-1} \cdot \mathrm{kg}^{-1}\right)\end{array}$ & $\begin{array}{l}\text { The level of significance of } \\
\text { the t-criterion }\end{array}$ \\
\hline & $\overline{\mathrm{X}} \pm S$ & $t ; p$ & $\overline{\mathrm{X}} \pm \mathrm{S}$ & $t ; p$ \\
\hline \multirow{3}{*}{$\begin{array}{l}\text { Endomorphic } \\
n=49\end{array}$} & $2517.9 \pm 302.40$ & $\mathrm{t}=8.73 ; \mathrm{p}=0.000^{*}$ & $37.8 \pm 3.41$ & $t=2.65 ; p=0.009 *$ \\
\hline & & $t=-4.73 ; p=0.000 \bullet$ & & $t=-7.01 ; p=0.000 \bullet$ \\
\hline & & $t=6.40 ; p=0.000$ & & $t=1.74 ; p=0.086 \square$ \\
\hline \multirow{3}{*}{$\begin{array}{l}\text { Ectomorphic } \\
n=49\end{array}$} & $1981.8 \pm 305.39$ & $t=-8.73 ; p=0.0000$ & $35.8 \pm 3.89$ & $t=-2.65 ; p=0.0090$ \\
\hline & & $t=-12.30 ; p=0.000 \bullet$ & & $t=-9.23 ; p=0.000 \bullet$ \\
\hline & & $t=-0.84 ; p=0.402 \square$ & & $t=-0.59 ; p=0.554 \square$ \\
\hline \multirow{2}{*}{$\begin{array}{l}\text { Endomorphic- } \\
\text { mesomorphic }\end{array}$} & $2850.8 \pm 407.18$ & $\mathrm{t}=12.30 ; \mathrm{p}=0.000^{*}$ & $42.7 \pm 3.82$ & $t=9.23 ; p=0.000^{*}$ \\
\hline & & $t=4.73 ; p=0.000 \circ$ & & $t=7.01 ; p=0.000 \circ$ \\
\hline$n=58$ & & $t=10.19 ; p=0.000$ & & $t=7.79 ; p=0.000$ \\
\hline Balanced & $2044.3 \pm 430.50$ & $t=-6.40 ; p=0.000 \circ$ & $36.3 \pm 4.83$ & $t=-1.74 ; p=0.0860$ \\
\hline \multirow[t]{2}{*}{$n=54$} & & $t=0.84 ; p=0.402^{*}$ & & $t=0.59 ; p=0.554^{*}$ \\
\hline & & $t=-10.19 ; p=0.000 \bullet$ & & $t=-7.79 ; p=0.000 \bullet$ \\
\hline
\end{tabular}

Notes: 1. WAnT10 - Wingate anaerobic test for 10 seconds. 2. o-relative to the endomorphic somatotype; * - relative to the ectomorphic somatotype; $\bullet$ - relative to the endomorphic-mesomorphic somatotype; $\mathbf{-}$ - relatively balanced somatotype. 3. $t=-0.84 ; p=0.402-$ italicized data where $p>0.05$. 
Table 2. Power of anaerobic lactatic processes of energy supply of women 25-35 years with different somatotypes

\begin{tabular}{|c|c|c|c|c|}
\hline \multirow[t]{2}{*}{$\begin{array}{l}\text { Somatotype } \\
\text { groups }\end{array}$} & $\begin{array}{l}\text { WAnT30 } \\
\left(\mathrm{kg} \cdot \min ^{-1}\right)\end{array}$ & $\begin{array}{l}\text { The level of significance } \\
\text { of the t-criterion }\end{array}$ & $\begin{array}{l}\text { WAnT30 } \\
\left(\mathrm{kg} \cdot \mathrm{min}^{-1} \cdot \mathrm{kg}^{-1}\right)\end{array}$ & $\begin{array}{l}\text { The level of significance of } \\
\text { the t-criterion }\end{array}$ \\
\hline & $\bar{X} \pm S$ & $\mathrm{t} ; \mathrm{p}$ & $\bar{X} \pm S$ & $t ; p$ \\
\hline \multirow{3}{*}{$\begin{array}{l}\text { Endomorphic } \\
n=49\end{array}$} & \multirow{3}{*}{$2303.3 \pm 287.95$} & $t=7.68 ; p=0.000^{*}$ & \multirow{3}{*}{$34.6 \pm 3.42$} & $\mathrm{t}=2.69 ; \mathrm{p}=0.008^{*}$ \\
\hline & & $t=-3.90 ; p=0.000 \bullet$ & & $t=-5.10 ; p=0.000 \bullet$ \\
\hline & & $t=6.33 ; p=0.000 \square$ & & $\mathrm{t}=2.75 ; \mathrm{p}=0.007 \mathrm{a}$ \\
\hline \multirow{3}{*}{$\begin{array}{l}\text { Ectomorphic } \\
n=49\end{array}$} & \multirow{3}{*}{$1780.2 \pm 380.03$} & $t=-7.68 ; p=0.0000$ & \multirow{3}{*}{$32.1 \pm 5.45$} & $t=-2.69 ; p=0.0080$ \\
\hline & & $t=-10.45 ; p=0.000 \bullet$ & & $t=-6.73 ; p=0.000 \bullet$ \\
\hline & & $t=-0.37 ; p=0.716 \square$ & & $t=0.06 ; p=0.952 \square$ \\
\hline \multirow{2}{*}{$\begin{array}{l}\text { Endomorphic- } \\
\text { mesomorphic }\end{array}$} & \multirow{3}{*}{$2569.1 \pm 396.55$} & $t=10.45 ; p=0.000^{*}$ & \multirow{3}{*}{$38.5 \pm 4.43$} & $t=6.73 ; p=0.000 *$ \\
\hline & & $t=3.90 ; p=0.0000$ & & $t=5.10 ; p=0.0000$ \\
\hline$n=58$ & & $t=9.25 ; p=0.000$ & & $t=6.85 ; p=0.000 a$ \\
\hline \multirow{3}{*}{$\begin{array}{l}\text { Balanced } \\
n=54\end{array}$} & \multirow{3}{*}{$1811.2 \pm 469.52$} & $t=-6.33 ; p=0.0000$ & \multirow{3}{*}{$32.0 \pm 5.57$} & $t=-2.75 ; p=0.0070$ \\
\hline & & $t=0.37 ; p=0.716^{*}$ & & $t=-0.06 ; p=0.952^{*}$ \\
\hline & & $\mathrm{t}=-9.25 ; \mathrm{p}=0.000 \bullet$ & & $t=-6.85 ; p=0.000 \bullet$ \\
\hline
\end{tabular}

Notes: 1 . WAnT30 - Wingate anaerobic test for 30 seconds. 2 . o-relative to the endomorphic somatotype; * - relative to the ectomorphic somatotype; $\bullet$ - relative to the endomorphic-mesomorphic somatotype; $\mathbf{-}$ - relatively balanced somatotype. 3 . $t=-0.37 ; p=0.716-$ italicized data where $p>0.05$.

According to the relative indicator of WAnT 30. representatives of endomorphic-mesomorphic somatotype have a statistically significant advantage over representatives of all other somatotypes $(p<0.05)$. WAnT $30_{\text {rel. }}$ value of representatives of endomorphic somatotype is statistically significantly greater than the value of ectomorphic and balanced somatotypes $(p<0.05)$. The values of ectomorphic and balanced somatotypes do not have a statistically significant difference $(\mathrm{p}>0.05)$ (table 2).

The study of the capacity of anaerobic lactatic processes of energy supply on the absolute indicator of MQMK revealed the advantage of representatives of endomorphic-mesomorphic somatotype over the values of all other somatotypes $(p<0.05)$. The value of MQMK representatives of endomorphic somatotype exceed the value of ectomorphic and balanced somatotypes $(p<0.05)$. And the value of the representatives of the ectomorphic somatotype exceeds the value of the representatives of the balanced somatotype, which is the lowest $(\mathrm{p}<0.05)$ (table 3).

The calculation of absolute indicator MQMK values per $\mathrm{kg}$ of body mass of the subjects revealed some differences. So the value of $\mathrm{MQMK}_{\text {rel. }}$ representatives of endomorphic-mesomorphic somatotype statistically significantly exceeds only the value of representatives of endomorphic and balanced somatotypes $(p<0.05)$. The values of representatives of ectomorphic somatotype exceed the values of endomorphic and balanced somatotypes $(p<0.05)$. The values of representatives of endomorphic and balanced somatotypes have no statistically significant difference $(\mathrm{p}>0.05)$.
The study of the threshold of anaerobic metabolism of women of different somatotypes in absolute terms revealed the predominance of endomorphic-mesomorphic somatotype over all other somatotypes $(\mathrm{p}<0.05)$. Between the values of TAM ${ }_{\text {abs. }}$ representatives of endomorphic, ectomorphic and balanced somatotypes, no statistically significant difference was found ( $\mathrm{p}>0.05)$ (table 4).

The calculation of the TAM indicator per $\mathrm{kg}$ of body mass of the subjects revealed the highest value in the representatives of the ectomorphic somatotype, which exceeds the value of the representatives of the endomorphic and endomorphic-mesomorphic somatotypes $(p<0.05)$. The value of $\mathrm{TAM}_{\text {rel. }}$ representatives of the balanced somatotype do not have a significant difference from the values of the ectomorphic somatotype $(p>0.05)$, but exceeds the value of the endomorphic and endomorphicmesomorphic somatotypes $(\mathrm{p}<0.05)$. Representatives of endomorphic-mesomorphic somatotype according to $\mathrm{TAM}_{\text {rel. }}$ dominated by representatives of the endomorphic somatotype $(\mathrm{p}<0.05)$ (table 4$)$.

The study of aerobic productivity of women of different somatotypes in absolute terms of $\mathrm{VO}_{2 \max }$ revealed the predominance of representatives of endomorphicmesomorphic somatotype over representatives of all other somatotypes $(\mathrm{p}<0.05)$. The value of $\mathrm{VO}_{2 \max }$ representatives of ectomorphic, endomorphic and balanced somatotypes do not have statistically significant differences $(\mathrm{p}>0.05)$ (table 5).

According to the relative indicator $\mathrm{VO}_{2 \max }$, a statistically significant advantage of representatives of ectomorphic and balanced somatotypes over representatives of endomorphic and endomorphic- 
Table 3. Capacity of anaerobic lactatic processes of energy supply of women 25-35 years of different somatotypes

\begin{tabular}{|c|c|c|c|c|}
\hline Somatotype & $\begin{array}{l}\text { MQMK } \\
\left(\mathrm{kg} \cdot \min ^{-1}\right)\end{array}$ & $\begin{array}{l}\text { The level of significance } \\
\text { of the t-criterion }\end{array}$ & $\begin{array}{l}\text { MQMK } \\
\left(\mathrm{kg} \cdot \mathrm{min}^{-1} \cdot \mathrm{kg}^{-1}\right)\end{array}$ & $\begin{array}{l}\text { The level of significance of } \\
\text { the t-criterion }\end{array}$ \\
\hline & $\bar{X} \pm S$ & $t ; p$ & $\bar{x} \pm S$ & $t ; p$ \\
\hline $\begin{array}{l}\text { Endomorphic } \\
n=49\end{array}$ & $1527.2 \pm 163.37$ & $\begin{array}{l}t=2.79 ; p=0.006^{*} \\
t=-5.17 ; p=0.000 \\
t=6.39 ; p=0.000\end{array}$ & $23.0 \pm 2.05$ & $\begin{array}{l}\mathrm{t}=-4.22 ; \mathrm{p}=0.000^{*} \\
\mathrm{t}=-5.72 ; \mathrm{p}=0.000 \\
\mathrm{t}=-0.20 ; p=0.841\end{array}$ \\
\hline $\begin{array}{l}\text { Ectomorphic } \\
n=49\end{array}$ & $1405.9 \pm 255.95$ & $\begin{array}{l}t=-2.79 ; p=0.0060 \\
t=-6.89 ; p=0.000 \bullet \\
t=2.55 ; p=0.012\end{array}$ & $25.4 \pm 3.52$ & $\begin{array}{l}t=4.22 ; p=0.0000 \\
t=-1.08 ; p=0.282 \\
t=3.91 ; p=0.000\end{array}$ \\
\hline $\begin{array}{l}\text { Endomorphic- } \\
\text { mesomorphic }\end{array}$ & $1734.9 \pm 237.84$ & $\begin{array}{l}t=6.89 ; p=0.000 * \\
t=5.17 ; p=0.0000\end{array}$ & $26.1 \pm 3.40$ & $\begin{array}{l}t=1.08 ; p=0.282^{*} \\
t=5.72 ; p=0.0000\end{array}$ \\
\hline$n=58$ & & $t=10.50 ; p=0.000$ & & $\mathrm{t}=5.38 ; \mathrm{p}=0.000$ \\
\hline $\begin{array}{l}\text { Balanced } \\
n=54\end{array}$ & $1288.5 \pm 209.94$ & $\begin{array}{l}t=-6.39 ; p=0.0000 \\
t=-2.55 ; p=0.012^{*} \\
t=-10.50 ; p=0.000\end{array}$ & $23.0 \pm 2.58$ & $\begin{array}{l}t=0.20 ; p=0.8410 \\
t=-3.91 ; p=0.000 * \\
t=-5.38 ; p=0.000\end{array}$ \\
\hline
\end{tabular}

Notes: 1. MQMK - maximum quantity of mechanical work for 1 minute. 2. o-relative to the endomorphic somatotype; * - relative to the ectomorphic somatotype; $\bullet$ - relative to the endomorphic-mesomorphic somatotype; $\mathbf{-}-$ relatively balanced somatotype. 3 . $t=-0.20 ; p=0.841$ - italicized data where $p>0.05$.

Table 4. The threshold of anaerobic metabolism of women 25-35 years of different somatotypes

\begin{tabular}{|c|c|c|c|c|}
\hline Somatotype & TAM (W) & $\begin{array}{l}\text { The level of significance } \\
\text { of the t-criterion }\end{array}$ & $\operatorname{TAM}\left(\mathbf{W} \cdot \mathbf{k g}^{-1}\right)$ & $\begin{array}{l}\text { The level of significance of } \\
\text { the t-criterion }\end{array}$ \\
\hline & $\bar{X} \pm S$ & $t ; p$ & $\bar{X} \pm S$ & $t ; p$ \\
\hline $\begin{array}{l}\text { Endomorphic } \\
n=49\end{array}$ & $138.6 \pm 12.91$ & $\begin{array}{l}t=0.87 ; p=0.384^{*} \\
t=-4.15 ; p=0.000 \bullet \\
t=1.94 ; p=0.055\end{array}$ & $2.1 \pm 0.26$ & $\begin{array}{l}t=-7.79 ; p=0.000^{*} \\
t=-3.05 ; p=0.003 \bullet \\
t=-6.56 ; p=0.000\end{array}$ \\
\hline $\begin{array}{l}\text { Ectomorphic } \\
n=49\end{array}$ & $136.3 \pm 12.53$ & $\begin{array}{l}t=-0.87 ; p=0.3840 \\
t=-5.04 ; p=0.000 \bullet \\
t=1.09 ; p=0.278\end{array}$ & $2.5 \pm 0.21$ & $\begin{array}{l}t=7.79 ; p=0.0000 \\
t=4.56 ; p=0.000 \bullet \\
t=1.91 ; p=0.059\end{array}$ \\
\hline $\begin{array}{l}\text { Endomorphic- } \\
\text { mesomorphic } \\
n=58\end{array}$ & $149.8 \pm 14.80$ & $\begin{array}{l}t=5.04 ; p=0.000 * \\
t=4.15 ; p=0.0000 \\
t=6.08 ; p=0.000\end{array}$ & $2.3 \pm 0.27$ & $\begin{array}{l}t=-4.56 ; p=0.000 * \\
t=3.05 ; p=0.0030 \\
t=-3.12 ; p=0.002\end{array}$ \\
\hline $\begin{array}{l}\text { Balanced } \\
n=54\end{array}$ & $133.5 \pm 13.48$ & $\begin{array}{l}t=-1.94 ; p=0.0550 \\
t=-1.09 ; p=0.278^{*} \\
t=-6.08 ; p=0.000 \bullet\end{array}$ & $2.4 \pm 0.19$ & $\begin{array}{l}\mathrm{t}=6.56 ; \mathrm{p}=0.0000 \\
t=-1.91 ; p=0.059^{*} \\
\mathrm{t}=3.12 ; \mathrm{p}=0.002\end{array}$ \\
\hline
\end{tabular}

Notes: 1. TAM - threshold of anaerobic metabolism. 2. o - relative to the endomorphic somatotype; ${ }^{*}-$ relative to the ectomorphic somatotype; $\bullet$ - relative to the endomorphic-mesomorphic somatotype; $\mathbf{\square}$ - relatively balanced somatotype. 3 . $t=0.87 ; p=0.384-$ italicized data where $p>0.05$. 
Table 5. Power of aerobic processes of energy supply of women 25-35 years of different somatotypes

\begin{tabular}{|c|c|c|c|c|}
\hline \multirow{2}{*}{$\begin{array}{l}\text { Somatotype } \\
\text { groups }\end{array}$} & $\begin{array}{l}\mathrm{VO}_{2 \max } \\
\left(\mathrm{ml} \cdot \mathrm{min}^{-1}\right)\end{array}$ & $\begin{array}{l}\text { The level of significance } \\
\text { of the t-criterion }\end{array}$ & $\begin{array}{l}\mathrm{VO}_{2 \max } \\
\left(\mathrm{ml} \cdot \mathrm{min} \cdot \mathrm{kg}^{-1}\right)\end{array}$ & $\begin{array}{l}\text { The level of significance } \\
\text { of the t-criterion }\end{array}$ \\
\hline & $\bar{X} \pm S$ & $t ; p$ & $\overline{\mathrm{X}} \pm \mathrm{S}$ & $t ; p$ \\
\hline \multirow{3}{*}{$\begin{array}{l}\text { Endomorphic } \\
n=49\end{array}$} & \multirow{3}{*}{$2509.9 \pm 116.43$} & $t=0.72 ; p=0.475^{*}$ & \multirow{3}{*}{$37.8 \pm 2.97$} & $\mathrm{t}=-11.11 ; \mathrm{p}=0.000^{*}$ \\
\hline & & $t=-6.13 ; p=0.000 \bullet$ & & $\mathrm{t}=-3.99 ; \mathrm{p}=0.000 \bullet$ \\
\hline & & $t=1.91 ; p=0.059$ & & $t=-7.99 ; p=0.000$ \\
\hline \multirow{3}{*}{$\begin{array}{l}\text { Ectomorphic } \\
n=49\end{array}$} & \multirow{3}{*}{$2487.0 \pm 190.65$} & $t=-0.72 ; p=0.4750$ & \multirow{3}{*}{$45.2 \pm 3.59$} & $t=11.11 ; p=0.000 \circ$ \\
\hline & & $t=-5.67 ; p=0.000 \bullet$ & & $\mathrm{t}=6.51 ; \mathrm{p}=0.000 \bullet$ \\
\hline & & $t=1.06 ; p=0.293 \square$ & & $t=1.38 ; p=0.172 \square$ \\
\hline \multirow{2}{*}{$\begin{array}{l}\text { Endomorphic- } \\
\text { mesomorphic }\end{array}$} & \multirow{3}{*}{$2681.1 \pm 163.61$} & $t=5.67 ; p=0.000^{*}$ & \multirow{3}{*}{$40.5 \pm 3.85$} & $t=-6.51 ; p=0.000^{*}$ \\
\hline & & $t=6.13 ; p=0.0000$ & & $t=3.99 ; p=0.0000$ \\
\hline $\mathrm{n}=58$ & & $t=6.67 ; p=0.000 \square$ & & $t=-4.42 ; p=0.000$ ? \\
\hline \multirow{3}{*}{ Balanced } & \multirow{3}{*}{$2445.2 \pm 209.38$} & $t=-1.91 ; p=0.0590$ & \multirow{3}{*}{$44.1 \pm 4.70$} & $t=7.99 ; p=0.000 \circ$ \\
\hline & & $t=-1.06 ; p=0.293^{*}$ & & $t=-1.38 ; p=0.172^{*}$ \\
\hline & & $t=-6.67 ; p=0.000 \bullet$ & & $t=4.42 ; p=0.000 \bullet$ \\
\hline
\end{tabular}

Notes: 1 . VO2max - maximum oxygen consumption. 2. 0 - relative to the endomorphic somatotype; ${ }^{*}-$ relative to the ectomorphic somatotype; - - relative to the endomorphic-mesomorphic somatotype; $\mathbf{-}$ - relatively balanced somatotype. 3 . $t=0.72 ; p=0.475-$ italicized data where $p>0.05$.

mesomorphic somatotypes was revealed $(\mathrm{p}<0.05)$. The value of $\mathrm{VO}_{2 \max \text { rel. }}$ representatives of endomorphicmesomorphic somatotype exceeds the value of representatives of endomorphic somatotype $(p<0.05)$.

\section{Discussion}

Investigating the anaerobic alactic productivity of girls aged 16-20 years, Dulo [9] found significantly higher absolute and relative values of WAnT10 indicator for women of endomorphic-mesomorphic somatotype. In addition, the author found that women of endomorphic and balanced somatotypes are characterized by lower values of absolute and relative values of WAnT10. Our results also indicate that among women 25-35 years in absolute and relative WAnT10 indicator have a predominance of representatives of endomorphic-mesomorphic somatotype. But the lowest results we found in representatives of ectomorphic and balanced somatotypes. Therefore, with age, anaerobic lactatic women productivity of different somatotypes may change. In our previous studies, we found that endomorphic and endomorphic-mesomorphic somatotypes representatives is differ by more body mass, and ectomorphic and balanced representatives - less. In addition, representatives of endomorphic-mesomorphic and ectomorphic somatotypes have higher percentages of muscle component [21]. Thus, we found that anaerobic lactatic productivity of women 25-35 years is at the highest level in representatives of somatotypes with greater body mass. The predominance of representatives of endomorphic-mesomorphic somatotype is due to high body mass values combined with a high percentage of muscle in the body. Such data indicate a probable high correlation anaerobic alactic productivity with the body's mass and the percentage of muscle in the body. Additional research is needed to confirm this hypothesis.

The peculiarities of anaerobic lactate productivity of the organism women aged 25-35 of different somatotypes according to WAnT 30 indicators have the same tendencies as according to WAnT10 indicator. Only according to the relative WAnT 30 indicator representatives of endomorphic somatotype have lost their advantage over women of balanced and ectomorphic somatotypes. According to Çinarli et al. [10] there is no statistically significant difference for men 22 years old among representatives of different somatotypes by the test WAnT30. In the literature, we did not find data on the peculiarities of the manifestation of WAnT 10 and WAnT 30 for women aged 25-35 of different somatotypes.

According to the absolute and relative indicators of the capacity of anaerobic lactatic productivity of the organism, the advantage of the representatives of the endomorphicmesomorphic somatotype was revealed. According to the absolute indicator of MQMK, a statistically significant difference was found between the representatives of all somatotypes in descending order: endomorphicmesomorphic, endomorphic, ectomorphic, balanced. According to the relative indicator of MQMK, the highest values are in the representatives of endomorphicmesomorphic and ectomorphic somatotypes. The lower values are in the women of endomorphic and balanced somatotypes. The data obtained by us are somewhat different from studies conducted with girls 17-19 years [5]. These differences relate to the relative rate of MQMK, as no statistically significant difference was found in girls 
aged 17-19 in representatives of different somatotypes. Thus, it can be argued that with age, for women the somatotype has a greater impact on anaerobic lactatic productivity.

According to the absolute indicator of the threshold of anaerobic metabolism, we found the advantage of the representatives of the endomorphic-mesomorphic somatotype over the representatives of all other somatotypes. According to the relative indicator of TAM, the advantage of representatives somatotypes who have less body mass - ectomorphic and balanced - was revealed. Zimnitskaya et al. [6] also investigated the threshold of anaerobic metabolism of women 25-35 years old. The authors found the predominance of normosthenic type in absolute terms and the predominance of asthenic type in relative terms. It should be noted that the authors used a different method of somatotyping. Therefore, these results can be taken into account, but to compare with our data is incorrect.

The obtained data on aerobic productivity of women in the first period of adulthood agreed with the data of previous studies on aerobic productivity of girls aged 1719 [5]. For both age groups the advantage is endomorphicmesomorphic somatotype for the absolute value of $\mathrm{VO}_{2}$ ${ }_{\max }$, and the advantage is ectomorphic and endomorphic somatotypes for the relative value of $\mathrm{VO}_{2}$ max Larry Kenny et al. [22], J. Furman [18] consider the relative indicator of $\mathrm{VO}_{2 \max }$ more informative for the analysis of aerobic performance. Then it is possible to say that among 25-35 years old women the representatives of those somatotypes who have smaller body weight have the best aerobic opportunities. Rupasinghe et al. [23] claim that by the relative Vo2 max indicator among medical students is dominated by representatives with a predominance of ectomorphy. Since ectomorphy assumes low values of body mass relative to height, we can assume that these data are consistent with our results. Alkandari, et al. [24] found that for men and women aged 9 to 55 years, endomorphy has a strong negative impact on the ability to demonstrate aerobic capacity. Marangoz Irfan et al. [25] found in handball players aged 18-30 a high degree of negative correlation between $\mathrm{VO}_{2 \text { max }}$ and endomorphy. Kanae Oda et al. [26] found negative correlations between $\mathrm{VO}_{2 \text { max }}$ and body fat percentage in Japanese men and women aged 30-52. Similar data were obtained by Anjali Nilkanthappa Shete [27], who investigated girls aged 17-22 old. Such data are consistent with our studies, because according to our data, representatives of somatotypes where endomorphy dominates (endomorphic-mesomorphic and endomorphic) have lower values of $\mathrm{VO}_{2}$ max rel.

\section{Conclusions}

High values of absolute indicators of functional fitness in women of different somatotypes are associated with high values of body weight combined with a high percentage of muscle. Accordingly, for representatives of somatotypes with lower body weight are characterized by lower absolute values of all indicators of functional fitness. The calculation of absolute values per kilogram of body weight significantly changes the distribution only in terms of aerobic productivity (VO2 max and TAM). According to the relative indicators of aerobic productivity, representatives of somatotypes, which are characterized by lower body mass, predominate.

The data obtained by us must be taken into account when analyzing the indicators of functional fitness of women who do not play sports. Also, these data must be taken into account when developing standards of functional readiness. The result of a woman of a certain somatotype can be significantly inferior (or superior) to the average level set for women without taking into account the somatotype, while corresponding to the average level for this somatotype.

\section{Acknowledgements}

The authors financed the study on their own.

\section{Conflict of interest}

The authors state that there is no conflict of interest.

\section{References}

1. Goran Spori, Daniel Bok, Dinko Vuleta Jr, Dra`en Harasin. Impact of Body Composition on Performance in Fitness Tests among Personnel of the Croatian Navy. Coll. Antropol., 2011; 35(2): 335-339.

2. Sukanta Saha. Somatic and Body Composition Factors Underlying Aerobic Capacity. American Journal of Sports Science, 2015; 3(2): 36-40. https://doi.org/10.11648/j.ajss.20150302.12

3. Dulo OA, Furman UM. Comparative characteristics of aerobic productivity of girls with different somatotypes living in mountainous and lowland areas of Transcarpathia. Biomedical and biosocial anthropology, 2013; 20: 23-27.

4. Neha Parve, Madhuri Kulkarni, Hemangini Sarambekar. Study of Static Anthropometric Measurements and Body Somatotypes of Women. International Journal of Scientific and Research Publications, [Internet]. 2015; 5(9). [cited 2015 September]. Available from: http://www.ijsrp.org/
research-paper-0915.php?rp=P454571

5. Miroshnichenko V, Salnykova S, Bohuslavska V, Pityn M, Furman Yu, Iakovliv V, et al. Enhancement of physical health in girls of 17-19 years by adoption of physical loads taking their somatotype into account. Journal of Physical Education and Sport, 2019; 58(2): 387-392. https://doi.org/10.7752/jpes.2019.s2058

6. Zimnitskaya R, Paramonova N. Dmitrii Jakubovskii. Comparative analysis of functional state and working capacity on veloergometer of average training level women of age. Sporto Mokslas, 2017; 1(87): 32-37. https://doi.org/10.15823/sm.2017.5

7. Ryan-Stewart H, Faulkner J, Jobson S. The influence of somatotype on anaerobic performance. $\quad P L o S \quad O N E, \quad 2018 ; 13: \mathrm{e} 0197761$. https://doi.org/10.1371/journal.pone.0197761

8. Furman YuM, Miroshnichenko VM, Brezdeniuk OYu, Furman TYu. An estimation of aerobic and anaerobic productivity 
of an organism of youth 17-19 years old of Podilsk region. Pedagogics, Psychology, Medical-Biological Problems of Physical Training and Sports, 2018; 22(3): 136-141. https://doi.org/10.15561/18189172.2018.0304

9. Dulo OA. Comparative characteristics of anaerobic productivity in girls with different somatotypes living in mountainous and lowland areas of the Transcarpathian region. Scientific Bulletin of Uzhhorod University, series "Medicine", 2015; 1 (51): 284-289.

10.Çinarli FS, Kafkas ME. The effect of somatotype characters on selected physical performance parameters. Physical Education of Students, 2019; 23(6): 279-287. https://doi.org/10.15561/20755279.2019.0602

11.TKornienko IA, Son'kin VD, Tambovtseva RV, Panasyuk TV. Thedevelopmentoftheenergeticsofskeletalmusclesdepending on the somatotype. Human Physiology, 2007; 33(6): 742-746. https://doi.org/10.1134/S0362119707060126

12.Kaur G, Singh SP, Singh A.P. Age Related Variations in Endomorphic, Mesomorphic and Ectomorphic Components of Somatotype in Urban Women of Punjab. Human Biology Review, 2017; 6(1): 47-52.

13.Nikolic S, Todorovska L, Maleska V, Dejanova B, Efremova L, Zivkovic V, Pluncevic-Gligoroska J. Analysis of Body Mass Components in National Club Football Players in Republic of Macedonia. Med. Arch., 2014: 68(3): 191-194. https://doi.org/10.5455/medarh.2014.68.191-194

14.Carter J, Heath B. Somatotyping - development and applications. Cambridge University Press; 1990.

15.Karpman VL, Gudkov IA, Koydikova GA. Indirect determination of maximum oxygen consumption of highly skilled athletes. Theory and Practice of Physical Culture, 1972; $1: 37-41$.

16.Mackenzie B. PWC-170 Cycle Test. Brianmac Sports Coache, [Internet]. 2002. [updated 2021 April 23; cited 2021 Jun 30]: .Available from: https://www.brianmac.co.uk/ pwc170.htm

17.Conconi F, Ferrari M, Ziglio PG, Droghetti P, Codeca L. Determination of anaerobic threshold by a noninvasive field test in runners. J. Appl. Physiol, 1982; 52: 869-873. https://doi.org/10.1152/jappl.1982.52.4.869

18.Furman YuM, Miroshnichenko VM, Drachuk SP Promising models of physical culture and health technologies in physical education of students of higher educational institutions. Kyiv: Olympic literature; 2013.
19.Szögÿ A, Cherebeţiu G. Minutentest auf dem Fahrradergometer zur Bestimmung der anaeroben Kapazität. Europ. J. Appl. Physiol, 1974; 33: 171-176. https://doi.org/10.1007/BF00449517

20.Bar-Or O. The Wingate anaerobic test: An update on methodology, reliability and validity. .Sports Medicine, 1987; 4: 381-394. https://doi.org/10.2165/00007256-198704060-00001

21.Miroshnichenko V, Salnykova S, Brezdeniuk O, Nesterova S, Sulyma A, Onyshchuk V, Gavrylova NV. The maximum oxygen consumption and body structure component of women at the first period of mature age with a different somatotypes. Pedagogics, Psychology, Medical-Biological Problems of Physical Training and Sports, 2018; 22(6): 306-312. https://doi.org/10.15561/18189172.2018.0605

22.W Larry Kenney, Jack H Wilmore, David L Costill. Physiology of Sport and Exercise. Human Kinetics; 2019.

23.Rupasinghe SD, Samarakoon KMHE, Samarakoon SMHKDS, Rathnayake RMUK, Samarakoon NK, Samarasinghe PRMR, et al. Distribution of somatotypes between categories of $\mathrm{VO}_{2}$ max among a selected group of individuals. Proceedings of the Peradeniya Univ. International Research Sessions, 2014; 18(4): 292.

24.Alkandari JR, Barac Nieto M. Somatotype Components, Aerobic Fitness and Grip Strength in Kuwaiti Males and Females. Health, 2016; 8: 1349-1355. https://doi.org/10.4236/health.2016.813135

25.Marangoz İrfan, Var Sevde Mavi. The Relationship among Somatotype Structures, Body Compositions and Estimated Oxygen Capacities of Elite Male Handball Players. Asian Journal of Education and Training, 2018; 4(3): 216-219. https://doi.org/10.20448/journal.522.2018.43.216.219

26.Kanae Oda, Nobuyuki Miyatake, Noriko Sakano, Takeshi Saito, Motohiko Miyachi, Izumi Tabata, et al. Relationship between peak oxygen uptake and regional body composition in Japanese subjects. Journal of Sport and Health Science, 2014; 3(3): 233-238. https://doi.org/10.1016/j.jshs.2012.11.006

27.Anjali Nilkanthappa Shete. A Study of $\mathrm{VO}_{2 \text { Max }}$ and Body Fat Percentage in Female Athletes. Journal of Clinical and Diagnostic Research, 2014; 8(12): 1-3. https://doi.org/10.7860/JCDR/2014/10896.5329 


\section{Information about the authors:}

Viacheslav M. Miroshnichenko; (Corresponding Author); https://orcid.org/0000-0003-1139-4554; 29miroshnichenko@ gmail.com; Vinnytsia Mykhailo Kotsiubynskyi State Pedagogical University; Vinnytsia, Ukraine.

Yuriy M. Furman; https://orcid.org/0000-0002-5206-7712; furman-dok@ukr.net; Vinnytsia Mykhailo Kotsiubynskyi State Pedagogical University; Vinnytsia, Ukraine.

Viktoriia Yu. Bohuslavska; https://orcid.org/0000-0003-3609-5518; Vik.bogusl@gmail.com;Vinnytsia Mykhailo Kotsiubynskyi State Pedagogical University; Vinnytsia, Ukraine.

Oleksandra Yu. Brezdeniuk; http://orcid.org/0000-0003-0844-8777; sandrikk86@gmail.com; Vinnytsia Mykhailo Kotsiubynskyi State Pedagogical University; Vinnytsia, Ukraine.

Svitlana V. Salnykova; https://orcid.org/0000-0003-4675-6105; aqvasveta@ukr.net; Vinnytsia Institute of Trade and Economics of Kyiv National University of Trade and Economics; Vinnytsia, Ukraine.

Oksana P. Shvetsi http://orcid.org/0000-0001-8038-1533; o.shvets1802@gmail.com; Vinnytsia Mykhailo Kotsiubynskyi State Pedagogical University; Vinnytsia, Ukraine.

Maryna O. Boiko; https://orcid.org/0000-0003-0539-2966; mzugrava@gmail.com; Vinnytsia Mykhailo Kotsiubynskyi State Pedagogical University; Vinnytsia, Ukraine.

Cite this article as:

Miroshnichenko VM, Furman YM, Bohuslavska VYu, Brezdeniuk OYu, Salnykova SV, Shvets OP, Boiko MO. Functional preparedness of women of the first period of mature age of different somatotypes. Pedagogy of Physical Culture and Sports, 2021;25(5):296-304. https://doi.org/10.15561/26649837.2021.0504

This is an Open Access article distributed under the terms of the Creative Commons Attribution License, which permits unrestricted use, distribution, and reproduction in any medium, provided the original work is properly cited (http://creativecommons.org/licenses/by/4.0/deed.en).

Received: 01.07.2021

Accepted: 11.08.2021; Published: 30.10.2021 